\title{
PELATIHAN PEMBUATAN MEDIA PEMBELAJARAN INTERAKTIF MENGGUNAKAN APLIKASI LECTORA DI SMK MUHAMMADYAH 1 PADANG
}

\author{
Karmila Suryani $^{1}$, Khairudin ${ }^{2}$ \\ ${ }^{1}$ Program Studi Pendidikan Teknik Informatika dan Komputer FKIP Universitas Bung Hatta \\ ${ }^{2}$ Program Studi Pendidikan Matemaika FKIP Universitas Bung Hatta \\ Jalan Sumatera, Ulak Karang, Padang Utara \\ 1e_mail: Kkarmila.suryani@bunghatta.ac.id
}

\begin{abstract}
Abstrak
Pemanfaatan media pembelajan berbasis Teknologi Informasi dan Komunikasi (TIK) merupakan salah satu tuntutan pemerintah kepada guru-guru agar proses pembelajaran lebih menarik. Namun saat ini sebagian besar dari guru-guru tidak dapat memanfaatkan TIK tersebut khususnya dalam penggunaan aplikasi Lectora sebagai media pembelajaran. Tujuan dari pelatihan ini adalah agar guru-guru dapat menghasilkan sebuah multimedia pembelajaran interaktif yang menarik sesuai dengan mata pelajaran masing-masing. Peserta dari pelatihan ini adalah guru produktif, adaptif dan normatif SMK Muhammadyah 1 Padang yang berjumlah 42 orang. Metode pelaksanaan pelatihan dilakukan dengan cara demonstrasi sekaligus praktikum di labor komputer yang dibagi menjadi 2 kelompok. Selanjutnya tahap akhir dilakukan evaluasi dengan menyebarkan angket untuk melihat sejauh mana keefektifan dari pelatihan yang telah dilaksanakan. Hasil dari pelatihan adalah guruguru telah mempunyai sebuah produk multimedia pembelajaran interaktif yang menarik dan dapat digunakan dalam pembelajaran, tegolong pada kategori baik dengan nilai $85,13 \%$.
\end{abstract}

Kata Kunci: Pelatihan, Multimedia Pembelajaran, Aplikasi Lectora, efektifitas pelatihan

\begin{abstract}
Utilization of Instructional media-based Information and Communication Technology (ICT) is one of the government's demands to the teachers for the learning process more interesting. But today most of the teachers can not utilize the ICT especially in the use of Lectora applications as a learning medium. The purpose of this training is for teachers to produce an interactive multimedia learning that is interesting in accordance with their respective subjects. Participants of this training are teachers productive, adaptive and normative SMK Muhammadyah 1 Padang, amounting to 42 people. The method of training implementation is done by demonstration as well as practicum in computer labor which is divided into 2 groups. The final stage is evaluated by spreading the questionnaire to see how far the effectiveness of the training has been done. The result of the training is that teachers have an interactive multimedia learning product that is interesting and can be used in learning. The results of the questionnaire evaluation show that this training is very well conducted in terms of preparation, material, delivery and consumption by $85.13 \%$.
\end{abstract}

Keywords: Training, Instructional Multimedia, Lectora Application, training effectifity 


\section{PENDAHULUAN}

Salah satu kebijakan kurikulum 2013 terhadap pembelajaran guru adalah pemanfaatan Teknologi Informasi dan Komunikasi (TIK) sebagai media pembelajaran guru untuk semua mata pelajaran, khususnya bagi guru Sekolah Menengah Kejuruan (SMK) (Bahan Uji Publik Kurikulum 2013 Kemendikbud, Slide ke-24). Dengan demikian, melalui kebijakan tersebut tuntutan kepada guru untuk merancang pembelajaran berbasis TIK (komputer) menjadi dasar utama dalam penyampaian informasi yang ingin disampaikannya.

Secara fundamental, kebijakan pemanfaatan media pembelajaran berbasis TIK untuk memberikan ketegasan kepada guru tentang urgensitas pembelajarannya yang tidak hanya mencakup kemampuan membelajarkan peserta didik, tetapi juga kemampuan guru dalam mengelola informasi yang akan disampaikannya dan mengorganisasi lingkungan pembelajaran yang dapat memberikan fasilitas bagi peserta didik untuk lebih mudah melakukan aktivitas belajar. Karena pada hakikatnya, pembelajaran berbasis TIK merupakan pembelajaran yang menuntut pengoptimalisasian TIK dalam setiap kegiatan pembelajaran. Lebih dalam Kemp dan Dayton (2003: 40) menjelaskan bahwa:

Computer based instruction refers to any application of computer technology to the instructional process. It includes using a computer to present information, to tutor a leaner, to provide practice for developing a skill, to simulate a process which is being studied, and manipulate to solve problem (Pembelajaran berbasis komputer mengacu pada penerapan teknologi komputer sebagai bagian dalam proses pembelajaran, seperti menggunakan komputer untuk menyajikan informasi, memberikan pelatihan untuk mengembangkan keterampilan, mensimulasikan proses yang sedang dipelajari dan memanipulasi pemecahan masalah).

Berdasarkan wawancara dengan Wakil Kepala sekolah SMK Muhammadyah 1 Padang, Bapak Wempi, S.Pd pada tanggal 30 Nopember 2017terungkap bahwa masih banyak guru yang belum mampu untuk membuat media pembelajaran yang menarik. Kebanyakan dari guru hanya menggunakan buku dan LKS sebagai media untuk mengantarkan materi pelajaran. Sementara 
sudah menjadi kewajiban bagi guru-guru untuk mengantarkan pembelajaran menggunakan media pembelajaran berbasis komputer. Pihak sekolah saat ini sudah menerapkan aturan agar guru-guru membuat sebuah media pembelajaran berbasis komputer untuk setiap materi pelajaran. Namun guru-guru hanya mampu menghasilkan media dalam bentuk slide presentasi menggunakan power point yang sederhana. Slide yang dihasilkan hanya bersifat satu arah di mana siswa hanya dapat membaca tanpa berinteraksi langsung dengan media. Disisi lain, ketika penulis mewawancarai beberapa guru produktif maupun guru-guru adaptif, terlihat bahwa untuk membuat sebuah media pembelajaran berbasis komputer yang menarik dan interaktif tidak mereka kuasai.

Disisi lain, sarana dan prasarana yang terdapat di sekoah sudah mencukupi untuk penggunaan multimedia pembelajaran, setiap guru sudah memiliki laptop dengan spesifikasi yang cukup tinggi, sekolah sudah mempunyai infokus agar guru dapat menampilkan media pembelajaran di kelas. Guru-guru yang mengikuti pelatihan adalah guru-guru yang mengampu mata pelajaran produktif dan normatif untuk semua jurusan yang ada di SMK Muhammadiyah 1 Padang. Guru-guru mata pelajaran normatf selama ini jarang menggunakan media berbasis komputer, apalagi menggunakan media dengan aplikasi lectora.

Dari permasalahan yang terjadi, maka penulis memberikan pelatihan pembuatan media pembelajaran pembelajan menggunakan aplikasi lectora yang lebih bersifat interaktif. Aplikasi lectora ini dilengkapi dengan fitur-fitur yang interaktif dan menarik seperti dapat memuat animasi dan video, dapat menampilkan hasil pada fitur evaluasi sehingga guru-guru dan siswa bisa langsung mengetahui nilai dari materi yang telah dipelajari.

\section{Tujuan Kegiatan}

Adapun tujuan dari kegiatan pengabdian ini adalah;

a. Guru-guru SMK Muhammadiyah 1 Padang mampu menghasilkan media pembelajaran mengunakan aplikasi lectora yang menarik dan interaktif sesuai dengan mata pelajaran masing-masing. 
b. Mampu meningkatkan kompetensi pedagogik dan kompetensi profesional guru dalam merancang media pembelajaran berbasis TIK dengan menggunakan aplikasi lectora

\section{METODE}

Metode yang digunakan dalam kegiatan Pengabdian Pada Masyarakat ini adalah pelatihan dalam menggunakan program aplikasi Lectora.

\section{Tahapan Pelaksanaan Pengabdian}

Ada 3 tahap yang dilakukan dalam kegiatan pengabdian ini antara lain sebagai berikut:

1) Tahap Persiapan

a. Survey lapangan dan konfirmasi dengan SMK Muhammadyah 1 Padang tentang kebutuhan materi PPM.

b. Diskusi internal tim tentang materi pelatihan.

c. Perancangan materi pelatihan dengan melakukan pertemuan dengan tim.

2) Tahap Pelaksanaan

a. Pelatihan tentang pengenalan aplikasi lectora sekaligus penggunaan menu icon yang digunakan.

b. Pelatihan mendisain media pembelajaran interaktif sesuai dengan mata pelajaran masing-masing.

3) Tahap Evaluasi dan Pelaporan

a. Evaluasi kemampuan guru SMK Muhammadyah 1 Padang dalam menghasilkan sebuah multimedia pembelajaran interaktif.

b. Pelaporan Kegiatan.

\section{Teknik Pengumpulan Data}

Dalam proses pelaksanaan kegiatan, tim PPM menggunkan teknik pengumpulan datanya dengan angket berupa kuesioner. Angket merupakan teknik pengumpulan data yang dilakukan dengan cara memberi seperangkat pertanyaan atau pertanyaan tertulis kepada responden untuk dijawabnya (Sugiyono, 2014:142). Angket yang digunakan merupakan angket tertutup, dimana komunikasi di lakukan dengan cara tidak langsung. Angket tertutup menurut 
Riduwan (2009:54) adalah "Angket yang disajikan dalam bentuk sedemikian rupa sehingga respon din minta memilih suatu jawaban yang sesuai dengan karakteristik dirinya dengan cara memberikan tanda silang (x) atau tanda checklist.

\section{Teknik Analisa Data}

Data ynag telah diperoleh dianalisa dalam bentuk evaluasi yang diberikan dengan memberikan angket tingkat kepuasan kepada peserta pelatihan setelah kegiatan pengabdian dilaksanakan. Para peserta dibimbing agar dapat menghasilkan multimedia interaktif menggunakan aplikasi lectora. Adapun indikator pada angket adalah A. Persiapan acara, B. Materi, C. Kegiatan pelatihan dan D. Pelayanan Konsumsi. Kriteria efektifitas pelaksanaan kegiatan seperti terlihat pada tabel 1 .

\begin{tabular}{|c|c|c|c|}
\hline \multirow{2}{*}{ No } & \multicolumn{2}{|c|}{$\begin{array}{r}\text { Skor Perolehan } \\
\text { Responden }\end{array}$} & \multirow{2}{*}{ Kriteria } \\
\cline { 2 - 3 } & Batas Skor & $\mathrm{p} \%$ & \\
\hline 1 & $0-1000$ & $0 \leq \mathrm{p} \leq 25$ & Jelek \\
\hline 2 & $1001-2000$ & $25<\mathrm{p} \leq 50$ & Cukup \\
\hline 3 & $2001-300$ & $50<\mathrm{p} \leq 75$ & Baik \\
\hline 4 & $3001-4000$ & $75<\mathrm{p} \leq 100$ & $\begin{array}{c}\text { Baik } \\
\text { Sekali }\end{array}$ \\
\hline
\end{tabular}

Tabel 1. Kriteria perolehan efektifitas pelatihan

Kriteria ini disesuaikan dengan perolehan skor total tiap kategori pada selang kontinum seperti yang ditunjukkan pada gambar 1 .

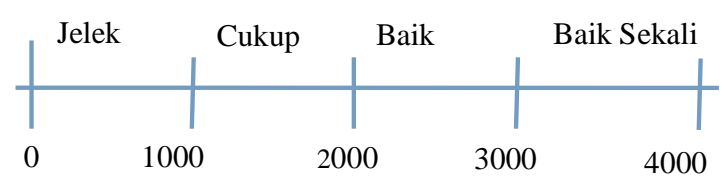

c.

\section{Gambar 1. Selang Kontinum untuk Kategori Pelatihan}

\section{Lokasi, Waktu dan Durasi Kegiatan}

Kegiatan ini dilaksanakan di SMK Muhammadyah 1 Padang, pada tanggal 27 April 2018. Kegiatan ini berlangsung selama satu hari mulai pukul 08.00 sampai dengan pukul 18.00WIB. 


\section{HASIL DAN PEMBAHASAN}

\section{Uraian Kegiatan}

Pelatihan pembuatan media pembelajaran interaktif menggunakan aplikasi lectora ini kegiatanya dilaksanakan di Sekolah Menengah Kejuruan (SMK) Muhammadyah 1 Padang. Kegiatan ini diawali dengan diskusi tim prodi Pendidikan Teknik Informatikan dan Komputer (PTIK) Fakultas Keguruan dan Ilmu Pendidikan Universitas Bung Hatta Padang dengan Kepala Sekolah (Bapak Zulkamil, M.T) dan wakil kurikulum (Bapak Wempi saputra, S.Pd) pada tanggal 2 Maret 2018. Hasil diskusi saat itu adalah kegiatan dilaksanakan setelah siswa/i SMK melaksanakan Ujian Nasional Berbasis Komputer (UNBK) sekitar bulan April.

Pada tanggal 13 April 2018 tim melakukan diskusi ke dua berkaitan dengan pelaksanaan pelatihan, dan disepakati bahwa pelatihan dilaksanakan pada tanggal 27 April 2018 mulai pukul 08.00 sampai dengan pukul 18.00 WIB. Pelatihan diikuti oleh 42 orang guru, baik guru yang mengajar mata pelajaran produktif maupun guru-guru yang mengajat mata pelajaran normatif. Sedangkan tim dosen sebagai instruktur berjumlah 9 orang dan 2 orang mahasiswa sebagai asisten instruktur. Kegiatan pelatihan ini dibuka dengan resmi oleh kepala sekolah (Bapak Zulkamil, M.T) dan dihadiri oleh wakil kepala sekolah (Bapak Wmpi Saputra, S.Pd) serta beberapa orang dari tenaga administrasi, seperti gambar 1.

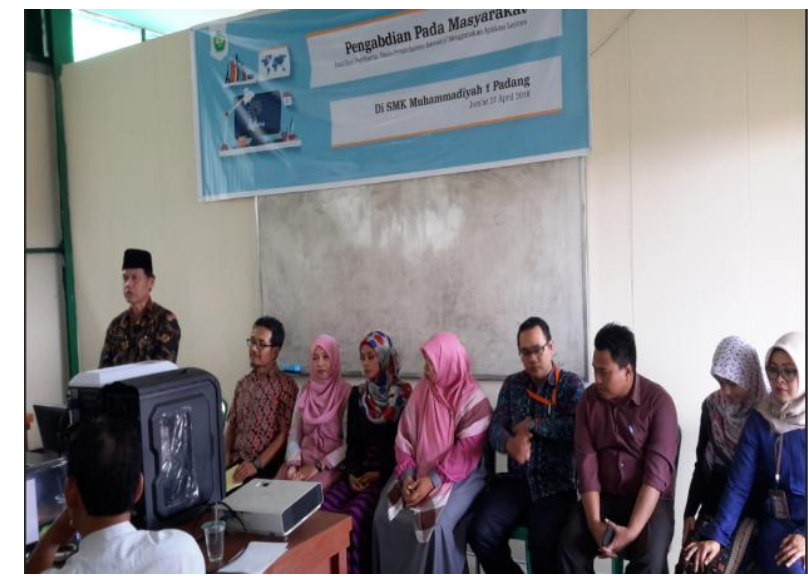

\section{Gambar 2. Pembukaan Oleh Kepala Sekolah}

Pelatihan ini dibagi menjadi 2 sesi, yaitu pukul 08.00 WIB sampai dengan pukul 12.00 WIB untuk sesi 1 dan sesi 2 dimulai pukul 14.00 sampai dengan 
pukul 18.00 WIB. Kegiatan dini dilaksanakan di labor komputer Teknik Komputer dan Jaringan (TKJ) dengan jumlah komputer 45 unit.

Sebelum sesi 1 dimulai maka tim sudah mempersiapkan program aplikasi Lectora yang harus diinstalkan telebih dahulu kesemua komputer yang ada. Beberapa tim terlibat dalam proses instalasi program aplikasi Lectora ini dan selebihnya membagikan materi yang telah dirancang kepada semua peserta pelatihan dalam bentuk hardcopy dan softcopy. Sesi 1 diantarkan oleh Bapak Dr. Eril Syahmaidi, M.Pd sementara tim yang lainya bertugas untuk mendampingi semua peserta agar dapat membantu peserta untuk lebih mudah mengikuti dan memahami materi yang diberikan instruktur. Materi yang disampaikan secara umum kemudian peserta menyelsaikan dengan bidang studi yang mereka ajarkan masing-masing. Sesi 2 dilanjutkan oleh ibu Ibu Karmila Suryani, M.Kom sebagai instruktur. Pada sesi ini peserta dibantu bagaimana untuk membuat soal yang bersifat objektif dan dasil nilainya dapat langsung ditampilkan dan bersifat random. Hal ini dapat membantu guru dalam mengevaluasi kemampuan dari siswanya. Apabila siswa sudah selesai menjawab semua pertanyaan di soal, maka sistim langsung mengolah nilainya sehingga siswa mengetahui langung berapa nilai yang mereka peroleh. Siswa bisa mencobakan sevaluasi berulang kali dan tentunya soal yang muncul tidak sama urutanya dengan soal yang telah siswa buka sebelumnya karena soal yang ditampilkan berikutnya bersifat acak. Setelah materi pembuatan soal ini selesai diantarkan maka semua peserta diminta untuk membuat 10 buah soal objektif sesuai dengan bidang studi mereka maasingmasing.

Dari hasil pengamatan tim selama proses pelatihan berlangsung, mulai dari sesi 1 sampai pada sesi 2, terlihat bahwa semua peserta sangat antuasis dalam pembuatan media pembelajaran menggunakan aplikasi lectora ini. Selama ini guru-guru hanya menggunakan slide presenasi sederhana dengan power point yang bersifat satu arah, namun sekarang guru-guru dapat mengahsilkan sebuah media pembelajaran interaktif yang bersifat dua arah dengan proses evaluasi yang bisa diproses langsung nilainya. Kegiatn Pelatihan dapat dilihat seperti gambar 2 dan 3. 


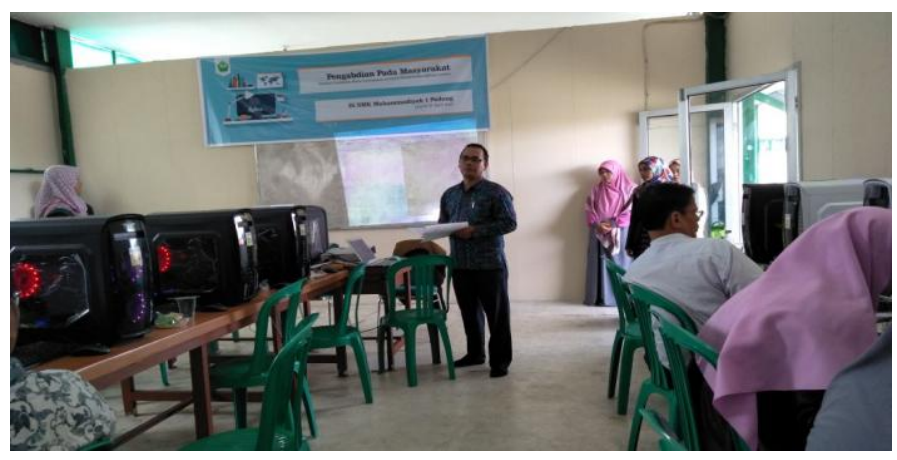

Gambar 3. Penyajian Materi

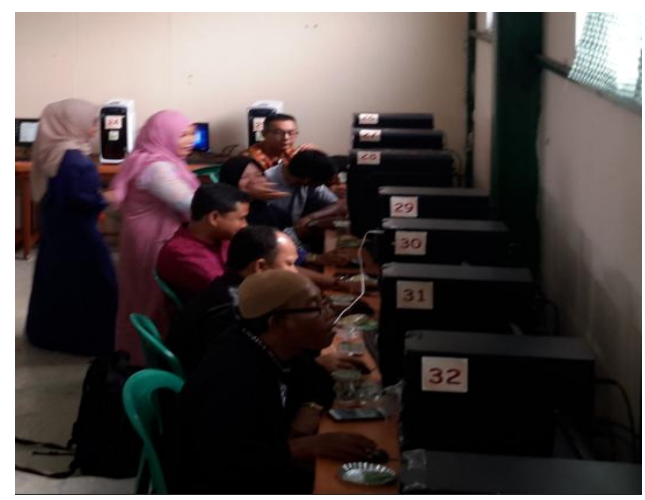

Gambar 4. Pendampiangan Pembuatan Multimedia Pembelajaran

\section{Hasil Evaluasi Pelaksanaan Kegiatan Pelatihan}

Hasil evaluasi pelaksanan kegiatan berada pada kategori baik sekali sesuai dengan selang kontunim pembagian skor yang tertera pada gambar 1. Perolehan skor rata-rata sebesar 3141 dengan persentase pelatihan sebesar 80,13\%. Evaluasi ini doperoleh dari angket yang diisi oleh 42 perserta pelatihan yang dibangikan setelah berakhir materi pelatihan.

\section{Hasil Kegiatan}

Kegiatan pelatihan pembuatan media pembelajaran interaktif menggunakan apikasi Lectora ini memperoleh hasil sebagai berikut:

1. Semua peserta mendapatkan pengetahuan baru tentang pembuatan media pembelajaran interaktif

2. Peserta menghasilkan sebuah media pembelajan interaktif sesuai dengan bidang studi masing-masing yang dilengkapi langsung dengan evaluasi berupa soal-soal objektif yang bersifat acak dan dapat langsung memunculkan nilainya. 
3. Adanya inisiasi untuk menjalin kegiatan yang diwujudkan dalam nota kesepahaman (MOU) antara prodi PTIK dengan SMK Muhammadyah 1 Padang

\section{Pembahasan}

Kegiatan pelatihan pembuatan multimedia pembelajaran menggunakan aplikasi Lectora ini berjaan sesuai dengan jadwal yang telah ditentukan. Semua peserta dapat menghasilkan sebuah multimedia pembelajaran interaktif yang dapat digunakan dalam proses pembelajaran dan lebih menarik. Para peserta menginginkan pelatihan lanjutan untuk pengolahan data nilai siswa secara otomatis sesuai dengan kurikulum 2013. Hal ini disepakati untuk pelaksanaan Pengabdian Pada Masyarakat tahun depan.

\section{SIMPULAN}

Dari kegiatan yang telah dilaksanakan dapat diambil beberapa kesimpulan antara lain;

1) Guru-guru telah mampu menghasilkan sebuah media pembelajan interaktif untuk satu materi sesuai dengan mata pelajaran masing-masing menggunakan aplikasi Lectora yang dilengkapi dengan evaluasi pembelajaran.

2) Dari angket yang diedarkan tentang kompetensi pedagogik dan profesional, maka $85 \%$ guru menjawab sudah mampu meningkatkan kemampuan mereka.

\section{UCAPAN TERIMA KASIH}

Terima kasih disampaikan kepada LPPM Universitas Bung Hatta yang telah mendanai keberlangsungan pengabdian kepada masyarakat, SMK Muhammadyah 1 Padang yang telah bersedia menerima dan menfasilitasi pengabdian kepada masyarakat yang telah dilakukan oleh tim dosen Universitas Bung Hatta.

\section{DAFTAR PUSTAKA}

Kementerian Pendidikan dan Kebudayaan. 2013. Petunjuk teknis Persiapan Implementasi Kurikulum 2013.

Riduwan.2009. Dasar-Dasar Statistika. Bandung: Alfabeta. 
Saripudin. 2015. Pengembangan model pembelajaran abad 21 dengan menggunakan teknologi Web 2.0. Jurnal Teknodik Vol 19 nomor 1.pp:1-11

Sugiyono . 2014. Metode Penelitian Kuantitatif, Kualitatif Dan R\&D. Bandung: Alfabeta.

Trust Action Program. 2015. Advance Competensy Training and Certification Office 2010/2007. Trust Press. Surabaya

UNESCO ICT Competency Framework for Teachers by the United Nations Educational. Scientific and Cultural Organization 7. place de Fontenoy. 75352 Paris 07 SP

Warsihna.J..2013. Pemanfaatan Teknologi Informatika dan Komunikasi (TIK) untuk pendidikan didaerah teencil. tertinggal dan terdepan(3T). Jurnal Teknodik Vol 17 Nomor 2.pp:238-245

Waldopo. 2015. Dampak pelatihan pemanfaatan Tik (PeTIK)untuk pembelajaran bagi guru di Sekolah Indonesia di luar negeri. urnal Teknodik Vol 19 nomor 1.pp:24-35 